\title{
Corrosion Inhibition Studies on Mild Steel in Acidic Media with 2-Hydroxy-4'-methoxy Chalcone
}

\author{
R. SURYA PRIYADHARSHINI and P. MOHAMED SIRAJUDEEN*
}

PG \& Research Department of Chemistry, Khadir Mohideen College, Adirampattinam-614 701, India

drpmsiraj@yahoo.in

Received 20 December 2015 / Accepted 19 January 2016

\begin{abstract}
The inhibition efficiency of 2-hydroxy-4'-methoxy chalcone on the corrosion of mild steel in $1 \mathrm{M} \mathrm{H}_{2} \mathrm{SO}_{4}$ was investigated by weight loss measurements and electrochemical studies at 303-323 K. Inhibition was found to increase with increasing concentration of the inhibitor but decreases with increasing temperature. Polarization curves showed that the inhibitor is mixed type but the cathode is more polarized than the anode. Electrochemical impedance showed that the presence of the inhibitor caused an increase in charge transfer resistance and decrease in double layer capacitance. The morphology of inhibited mild steel was analyzed by scanning electron microscopy with EDX. The synthesized chalcone was characterized by FTIR spectroscopy. Adsorption of the inhibitor on the metal surface was found to obey Langmuir adsorption isotherm.
\end{abstract}

Keywords: Mild steel, Chalcone, Weight loss, Inhibition, Temperature

\section{Introduction}

Mild steel is widely used in most industries due to its low cost and availability in ease for the fabrication of various reaction vessels such as cooling tower tanks, pipelines, etc $^{1}$. In most of the industries, acid solutions are generally used for the removal of rust and scale in several industrial processes. Sulphuric acid is often used as a pickling acid for steel and its alloys ${ }^{2}$. Hence the metals face a serous of corrosion problem. Although there are numerous options for controlling the corrosion of metals, the use of inhibitors is one of the best methods for protecting metals against corrosion. An inhibitor can be chosen from compounds that have hetero atoms in their aromatic ring system or made from cheap raw materials ${ }^{3}$. The inhibition process has been shown to occur via inhibitor adsorption isotherm and the efficiency of the inhibitors strongly depends on the structure and chemical characteristics of the adsorbed inhibitor layer formed under particular experimental conditions.

\section{Experimental}

Mild steel of the composition (wt\%) as: C-(0.06), Mn-(0.18), P-(0.02) and the remains iron was used for the study ${ }^{4}$. The mild steel coupons were prepared, degreased and cleaned as previously reported ${ }^{5-7}$. All reagents used $\left(\mathrm{H}_{2} \mathrm{SO}_{4}\right.$ and Ethanol) for the study were analar grade and deionized water was used for their preparation. 


\section{Inhibitor}

Chalcones were prepared by condensation of acetophenone with aromatic aldehydes in presence ofsuitable condensing agent ${ }^{8,9}$. They undergo a variety of chemical reactions that leads to many heterocyclic compounds ${ }^{10-13}$. 2-Hydroxy-4'methoxy chalcone was prepared and used as inhibitor to the present study shown in Figure 1.<smiles>COc1ccc(/C=C/C(=O)c2ccccc2O)cc1</smiles>

Figure 1. 2-Hydroxy-4'methoxy chalcone

The apparatus and procedure followed for weight loss method was similar to that earlier reports ${ }^{14-17}$. In the weight loss method, the progress of the corrosion reaction was monitored by determining the weight loss of the coupons (obtained as the differences in the weight of the coupons after immersion in solutions of the system and the original weight of the coupons) at fixed time intervals. In this technique, the experiment was conducted in the temperature range $30^{\circ}$ to $50{ }^{\circ} \mathrm{C}$ at intervals of $10{ }^{\circ} \mathrm{C}$ maintained in a thermostated bath.

\section{Potentiodynamic polarisation technique}

This method involves measurement of corrosion rate of the system. By the measurement of the potential of the electrode for various applied current densities, a plot of E vs. Log I gives a figure known as polarization diagram. The resulting current is plotted against the potential and slope of the line is measured. This instrument itself is having provisions for programs to evaluate corrosion kinetic parameters such as $\mathrm{I}_{\text {corr }}, \mathrm{E}_{\mathrm{corr}}, \mathrm{b}_{\mathrm{a}}$ and $\mathrm{b}_{\mathrm{c}}$

\section{Impedance measurements}

An electrochemical impedance measurement is an appropriate method for corrosion studies, particularly for corrosion rate determinations, mechanistic studies, passivation and passivity process and for investigation in inhibited systems. $R_{c t}$ or $R_{t}$ gives charge transfer resistance and $\mathrm{C}_{\mathrm{dl}}$ represents the double layer capacitance. Using Stern-Geary equation, $\mathrm{I}_{\mathrm{corr}}$ is obtained from $\mathrm{R}_{\mathrm{t}}$ since,

$$
I_{\text {corr }} \frac{b_{a} \times b_{c}}{2.303 x\left(b_{a}+b_{c}\right) R_{t}}
$$

\section{Spectroscopy methods}

FT-IR ${ }^{18-21}$ and UV-Visible ${ }^{22,23}$ spectroscopic techniques are useful for conforming the structure of inhibitor molecules. FT-IR studies help to predict the presence of chemical bonds in the inhibitor. UV-Visible absorption spectrum shows absorption bands corresponds to structural groups within the molecule.

\section{SEM analysis}

The specimens used for surface morphological examination were immersed in acid solutions with and without inhibitor for $2 \mathrm{~h}$. Then they were removed and dried and analysed. This analysis was performed on ZEISS -Supra40VP Scanning Electron Microscope. 


\section{Results and Discussion}

\section{Corrosion rates and inhibition efficiency}

The results are presented in Table 1. Chalcone was added as inhibitor to assess the effect of corrosion of mild steel in sulphuric acid. Inhibition efficiency has been calculated as follows:

$$
\text { I.E. } \%=\frac{\mathrm{Wu}-\mathrm{Wi}}{\mathrm{Wu}} \times 100
$$

where, $\mathrm{Wu}$ is the weight loss of metal in uninhibited acid and $\mathrm{Wi}$ is the weight loss of metal in inhibited acid.

Table 1. Inhibition efficiency of the inhibitors in $1 \mathrm{M}$ sulphuric acid at different temperatures

\begin{tabular}{ccccc}
\hline Temperature, $\mathrm{K}$ & $\begin{array}{c}\text { Concentration of } \\
\text { the inhibitor, } \\
\text { Mm }\end{array}$ & $\begin{array}{c}\text { Corrosion rate } \\
\times 10^{-2}, \text { mmpy }\end{array}$ & $\begin{array}{c}\text { Surface } \\
\text { coverage, } \theta\end{array}$ & $\begin{array}{c}\text { Inhibition } \\
\text { efficiency, \% }\end{array}$ \\
\hline 303 & Blank & 7.28 & - & - \\
& 0.003 & 2.29 & 0.7964 & 79.64 \\
& 0.006 & 1.28 & 0.8579 & 85.79 \\
& 0.012 & 1.17 & 0.8638 & 86.38 \\
313 & 0.024 & 0.91 & 0.8931 & 89.31 \\
& Blank & 10.71 & - & \\
& 0.003 & 2.35 & 0.6828 & 68.28 \\
& 0.006 & 1.58 & 0.8217 & 82.17 \\
323 & 0.012 & 1.47 & 0.8310 & 83.10 \\
& 0.024 & 1.15 & 0.8611 & 86.11 \\
& Blank & 24.19 & - & \\
& 0.003 & 10.30 & 0.5750 & 57.50 \\
& 0.006 & 9.59 & 0.6033 & 60.33 \\
& 0.012 & 7.19 & 0.6966 & 69.66 \\
& 0.024 & 4.80 & 0.7959 & 79.59 \\
\hline
\end{tabular}

Energy of activation (Ea) has been calculated from the (Figure 2) slope of log $\rho$ versus $1 / \mathrm{T}(\rho=$ corrosion rate, $\mathrm{T}=$ absolute temperature) and also with the help of the Arrhenius equation $^{24}$.

$$
\text { Slope }=\mathrm{Ea} / 2.303 R
$$

The results of the tables reveal that the rate of corrosion of mild steel in $1 \mathrm{M} \mathrm{H}_{2} \mathrm{SO}_{4}$ decreases with increase in inhibitor concentrations at all the temperatures studied. The increase in inhibition efficiency with increase in concentration of the compound studied can be explained on the basis of increased adsorption of the compound on the metal surface. As far as the inhibition process is concerned, it is generally assumed that the adsorption of the inhibitors at the metal/aggressive solution interface is the first step in the inhibition mechanism ${ }^{25}$.

\section{Effect of temperature}

Table 1 shows that as the temperature increases corrosion rate increases while percentage of I.E. decreases.The Efficiencies are found to be higher than that of uninhibited system. The higher values of Ea indicate physical adsorption of the inhibitors on metal surface ${ }^{26}$. The film formation of the inhibitor on the mild steel surface increases the values of activation energy. The values of Ea calculated from the slope of Arrhenius plot and using Eq. 3 are almost similar ${ }^{27}$. The values of entropy of activation $\left(\Delta S^{*}\right)$ is found to be -66.06 in the inhibited 
system and $-50.74 \mathrm{~J} \mathrm{~K}^{-1} \mathrm{~mol}^{-1}$ in $1 \mathrm{M}$ sulphuric acid. The negative values of entropy imply that the activated complex in the rate determining step represents association rather than dissociation $^{28}$. Various adsorption isotherms were verified to fit surface coverage $(\Theta)$ values but the best fit was found to obey Langmuir adsorption isotherm (Figure 3) which can be expressed as;

$$
\mathrm{C} / \theta=1 / \mathrm{K}_{\mathrm{ads}}+\mathrm{C}
$$

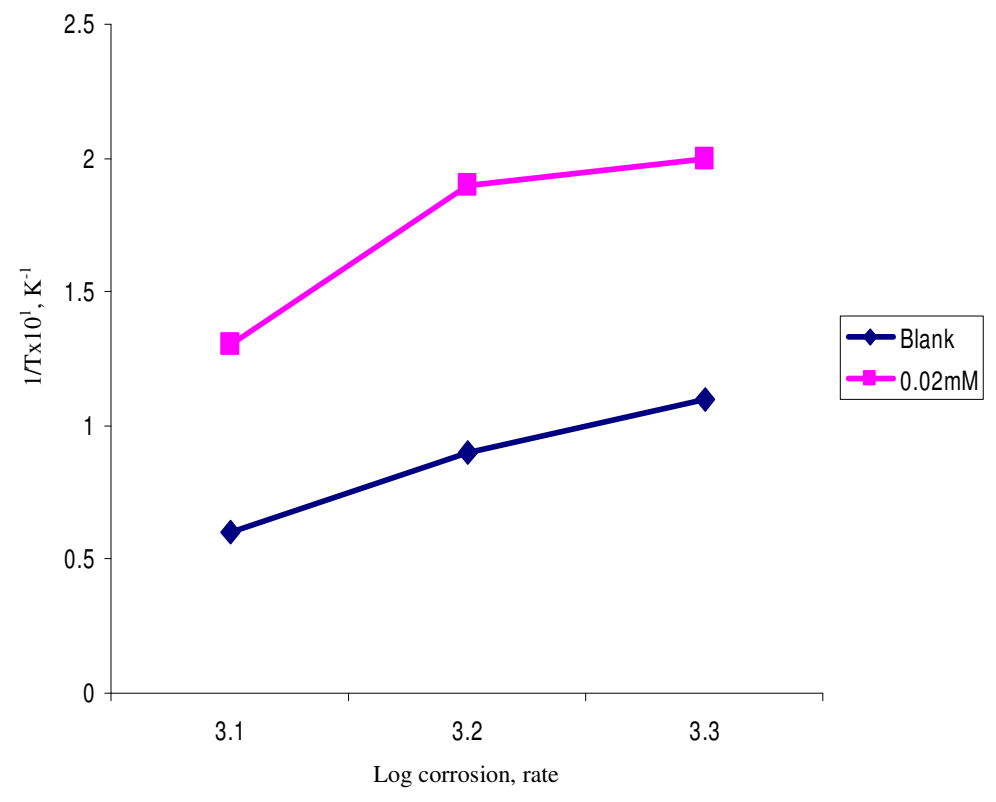

Figure 2. Arrhenius plot of corrosion of mild steel in $1 \mathrm{M} \mathrm{H}_{2} \mathrm{SO}_{4}$ solution in the absence and presence of inhibitor

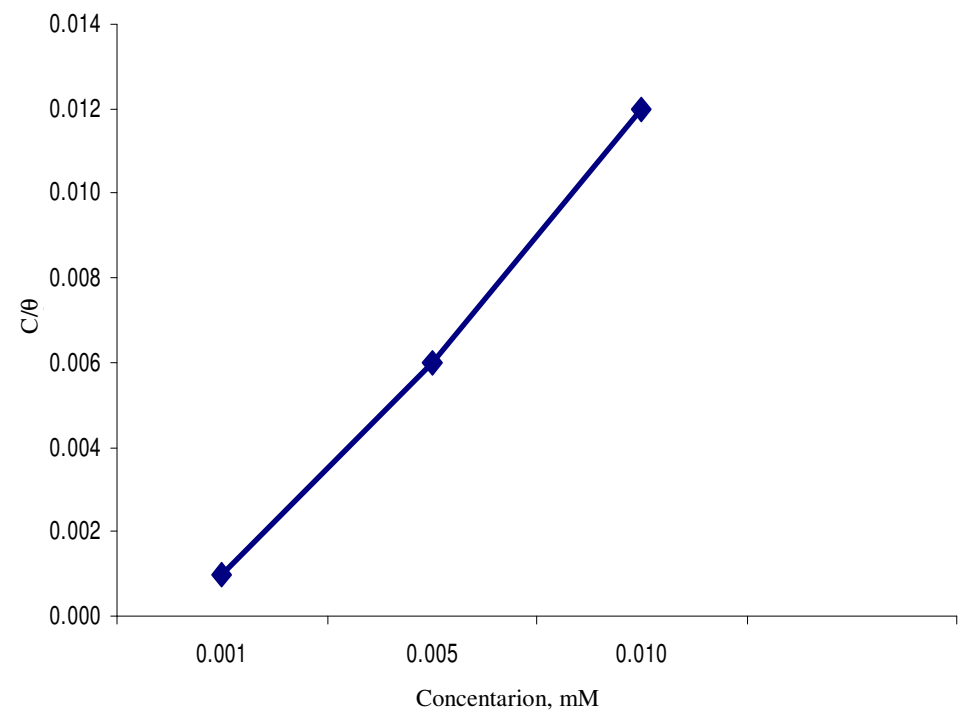

Figure 3. Arrhenius plot of corrosion rate of mild steel in $1 \mathrm{M} \mathrm{H}_{2} \mathrm{SO}_{4}$ in presence of inhibitor 
Where $C$ is inhibitor concentration, $\theta$ is surface coverage and $K_{a d s}$ is equilibrium constant of adsorption related to free energy of adsorption as;

$$
\mathrm{K}_{\mathrm{ads}}=1 / 55.5 \exp \left(-\Delta \mathrm{G}_{\mathrm{ads}}^{\mathrm{e}} / \mathrm{RT}\right)
$$

From Table 2 , it is evident that in all cases, the free energy of adsorption $\left(\Delta \mathrm{G}_{\mathrm{ads}}^{\circ}\right)$ values are negative and suggests that they are strongly adsorbed on the metal surface. This statement is supported by the work of Talati and Darji ${ }^{29}$.

Table 2. Polarization data of the inhibitor in $1 \mathrm{M}$ sulphuric acid at $30 \pm 0.1{ }^{\circ} \mathrm{C}$

\begin{tabular}{ccccccc}
\hline $\begin{array}{c}\text { Concentration } \\
\mathrm{Mm}\end{array}$ & $\begin{array}{c}\mathrm{E}_{\text {Corr }}, \\
\mathrm{mV}\end{array}$ & $\beta_{\mathrm{a}}, \mathrm{mV}$ & $\beta_{\mathrm{c}}, \mathrm{mV}$ & $\begin{array}{c}\mathrm{I}_{\text {Corr }} \\
\mathrm{mA} / \mathrm{cm}^{2}\end{array}$ & $\begin{array}{c}\text { Corrosion } \\
\text { rate, } \\
\mathrm{mmpy}\end{array}$ & $\begin{array}{c}\text { Inhibition } \\
\text { Efficiency } \\
\%\end{array}$ \\
\hline Blank & -388 & 108 & 139 & 9.466 & 109.71 & - \\
0.001 & -474 & 56 & 82 & 1.180 & 13.68 & 87.52 \\
0.02 & -479 & 35 & 73 & 0.391 & 4.54 & 95.85 \\
\hline
\end{tabular}

\section{Potentiodynamic polarization and impedance studies}

Potentiodynamic polarization results obtained for the inhibitory effect of 2-hydroxy-4'methoxy chalconeon mild steel corrosion in $1 \mathrm{M} \mathrm{H}_{2} \mathrm{SO}_{4}$ is portrayed in Figure 4 and in Table 3. The different polarization parameters such as corrosion current $\left(\mathrm{I}_{\text {corr }}\right)$, corrosion potential $\left(\mathrm{E}_{\mathrm{corr}}\right)$, anodic and cathodicTafel slopes $(\beta \mathrm{a}$ and $\beta \mathrm{c})$ were obtained from potentiodynamic polarization studies on mild steel in sulphuric acidic medium.

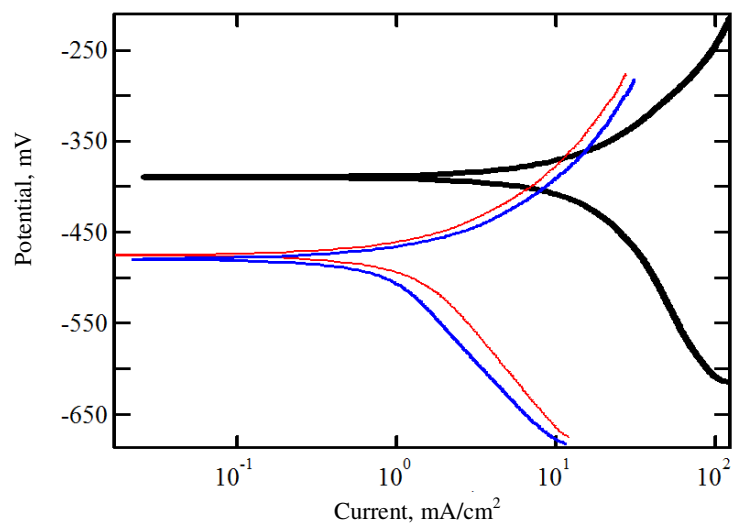

Figure 4. Polirization curves for mild steel in $1 \mathrm{M} \mathrm{H}_{2} \mathrm{SO}_{4}$ for selected concentrations of inhibitor

Table 3. Impedance data of the inhibitor in $1 \mathrm{M}$ sulphuric acid at $30 \pm 0.1{ }^{\circ} \mathrm{C}$

\begin{tabular}{ccccccc}
\hline $\begin{array}{c}\text { Concentration } \\
\mathrm{mM}\end{array}$ & $\mathrm{I}_{\text {Corr } \mathrm{mA} / \mathrm{cm}^{2}}$ & $\begin{array}{c}\text { Corrosion } \\
\text { rate, } \\
\text { mmpy }\end{array}$ & $\begin{array}{c}\mathrm{R}_{\mathrm{S}} \\
\text { ohm.cm }\end{array}$ & $\mathrm{R}_{\mathrm{ct}} \mathrm{ohm} \cdot \mathrm{cm}^{2}$ & $\begin{array}{c}\mathrm{C}_{\mathrm{dl}}(\mathrm{F}) \\
\mathrm{x} 10^{-5}\end{array}$ & $\begin{array}{c}\text { Inhibition } \\
\text { efficienct } \\
\%\end{array}$ \\
\hline Blank & 23.61 & 273.6 & 0.97 & 1.10 & 88.46 & - \\
0.001 & 1.40 & 16.27 & 3.45 & 18.58 & 1.94 & 94.05 \\
0.02 & 1.24 & 14.45 & 3.32 & 20.93 & 3.42 & 94.72 \\
\hline
\end{tabular}

It has been experimentally verified from the Table 3 that the $E_{\text {corr }}$ values have been shifted slightly towards negative side in the presence of inhibitors suggesting that the 
inhibitors inhibit the corrosion of mild steel in acidic solutions by controlling cathodic reactions due to the blocking of active sites on the metal surface. It is evident that inhibitors bring about considerable polarization of the cathode. It shows that the inhibitive action of 2-hydroxy-4'-methoxy chalcone is of mixed type inhibitor.

The $I_{\text {corr }}$ values have decreased for the inhibitor at optimum concentration. The inhibition efficiencies determined from the values of corrosion current density and the inhibition efficiency were found to show good agreement with those obtained from weight loss measurements. 2-Hydroxy-4'-methoxy chalcone shows the maximum inhibition efficiency of $95.85 \%$ in $1 \mathrm{M} \mathrm{H}_{2} \mathrm{SO}_{4}$. This result suggests that the addition of inhibitors retards the hydrogen evolution reaction ${ }^{30,31}$. Hence the 2 -hydroxy-4'-methoxy chalcone acts as a good inhibitor system due to the higher electrostatic attraction over the metal surface. This occur due to the presence of high electron density of the methoxy and hydroxy groups in the inhibitor molecule ${ }^{32}$.

The lower double layer capacitance $(\mathrm{Cdl})$ value for $1 \mathrm{M} \mathrm{H}_{2} \mathrm{SO}_{4}$ medium shown in Figure 5 and Table 4 indicates that the homogeneity of the surface of the mild steel roughened due to corrosion. The double layer capacitance $\mathrm{Cdl}$ values have decreased on the effective addition of inhibitor at the concentration $(0.02 \mathrm{mM})$. The studied system indicates the reduction of charge accumulated in the double layer due to formation of adsorbed inhibitor layer over the metal surface $\mathrm{e}^{33,34}$.

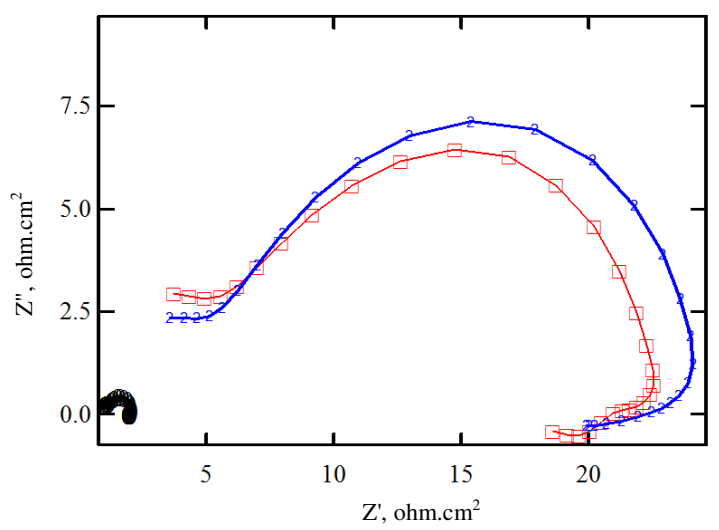

Figure 5. Nyquist plot for mild steel in1 $\mathrm{M} \mathrm{H}_{2} \mathrm{SO}_{4}$ for the selected concentrations of inhibitor

Table 4. Activation energies $\left(E_{a}\right)$ and free energies of adsorption $\left(\Delta G^{o}\right.$ ds $)$ for the corrosion of mild steel in $1 \mathrm{M}$ sulphuric acid

\begin{tabular}{ccccc}
\hline \multirow{2}{*}{$\begin{array}{c}\text { Concentration, } \\
\mathrm{mM}\end{array}$} & $\mathrm{E}_{\mathrm{a}}, \mathrm{kJ}$ & \multicolumn{3}{c}{$-\Delta \mathrm{G}^{\circ}{ }_{\mathrm{ads}}, \mathrm{kJ}$} \\
\cline { 3 - 5 } & & $303 \mathrm{~K}$ & $313 \mathrm{~K}$ & $323 \mathrm{~K}$ \\
\hline Blank & 38.29 & - & - & - \\
0.02 & 67.01 & 25.45 & 25.34 & 25.00 \\
\hline
\end{tabular}

\section{FT-IR and UV spectral studies}

Figure 6 shows the IR spectrum of the 2-hydroxy-4'-methoxy chalcone. In this spectrum the peak appeared at $3435 \mathrm{~cm}^{-1}$ corresponds to (OH stretching), $3008 \mathrm{~cm}^{-1}$ (C-H stretching, aromatic), $2841 \mathrm{~cm}^{-1}$ (C-H, aliphatic), $1676 \mathrm{~cm}^{-1}$ (C=O, stretching), $\sim 1600,1512,1456 \mathrm{~cm}^{-1}$ 
(C=C, aromatic, stretching, vibration), $1256 \mathrm{~cm}^{-1}$ (C-O stretching), 766, $835 \mathrm{~cm}^{-1}$ (disubstituted ortho, para). Figure 7 shows the UV spectrum of the inhibitor. The conjugated pi system in the inhibitor gives rise to a strong UV absorbance at $241 \mathrm{~nm}$ to $\pi-\pi^{*}$ transition and $\mathrm{n}-\pi^{*}$ tration at $318,383 \mathrm{~nm}$ due to $\mathrm{C}=\mathrm{O}$ and lone pair of oxygen in the molecule ${ }^{35,36}$.

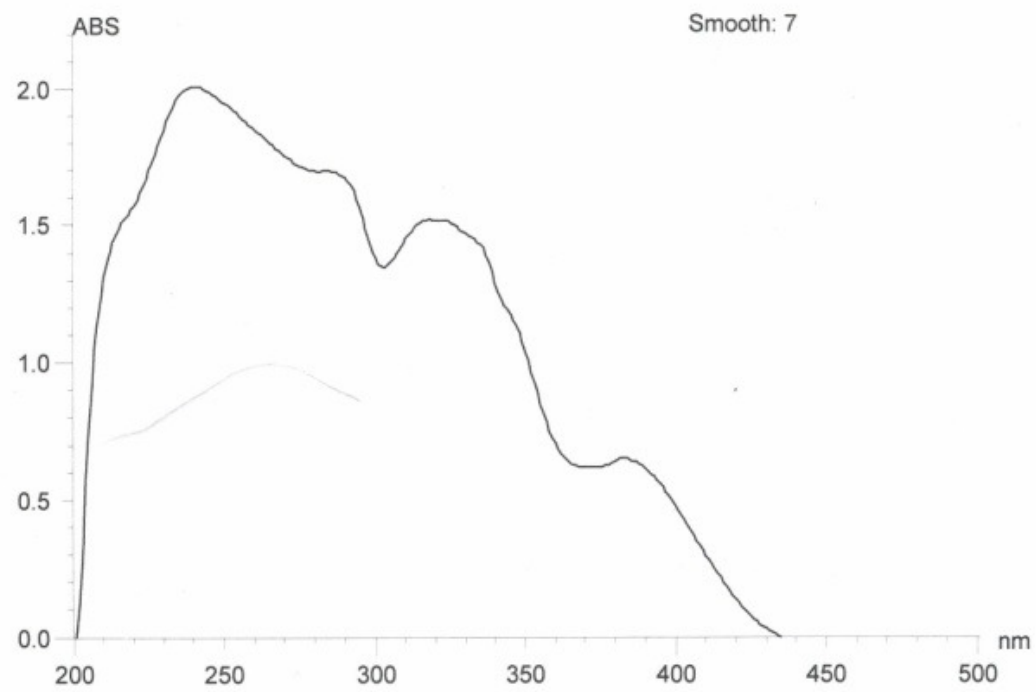

Figure 6. UV absorption spectra of the inhibitor

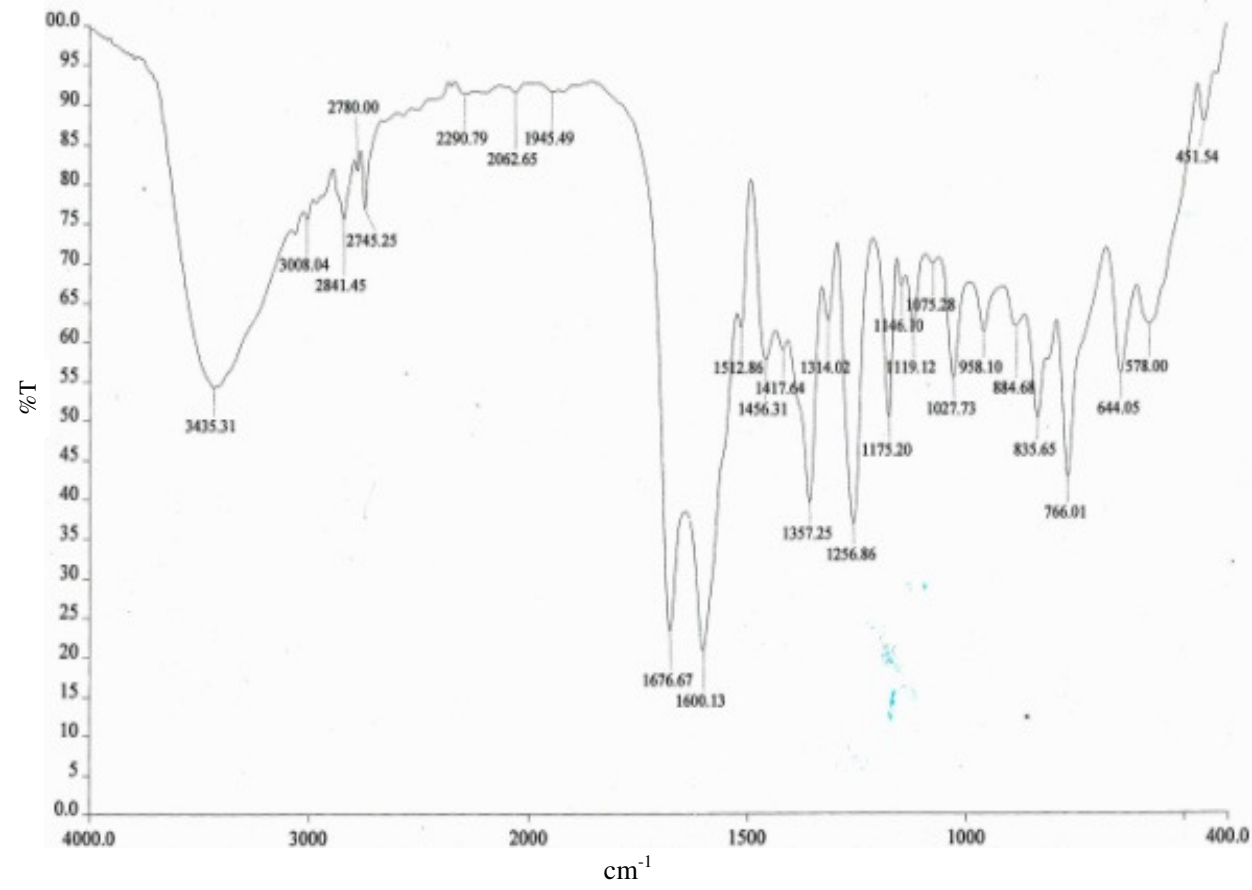

Figure 7. FTIR spectrum of the inhibitor 


\section{SEM studies}

The polished mild steel specimens were immersed in the acid solution $\left(1 \mathrm{MH}_{2} \mathrm{SO}_{4}\right)$ containing inhibitor 2-hydroxy-4'-methoxy chalcone for $2 \mathrm{~h}$ then the specimens were taken out, dried and observed under Scanning electron microscope (SEM). The SEM image of fresh metal is shown in Figure 8a. The morphology of experimental coupon shown in Figure 8b is very rough and the surface has been damaged due to metal dissolution in $1 \mathrm{MH}_{2} \mathrm{SO}_{4}$. The SEM image of the metal dipped in the acid containing $0.024 \mathrm{mM}$ of inhibitor is shown in Figure 8c. Presence of the inhibitor the corrosion rate was decreased and the surface damage was diminished considerably. The surface smoothness was improved by better coverage of inhibitor, so that there is a decrease in the contact between metal and the aggressive medium ${ }^{37}$. Table 5 (Figure 9a-c) shows the various composition of elements present in the fresh and exposed coupons. The table shows that the concentration of $\mathrm{Fe}, \mathrm{C}$ and $\mathrm{Mn}$ are found higher in the fresh metal than the inhibited and uninhibited acid medium. The concentration of $\mathrm{O}_{2}$ atoms are found lower than that of the blank metal sample. It reveals that the inhibitor act as a good barriers against the penetration of the aggressive ions in the solution to the metal sample.

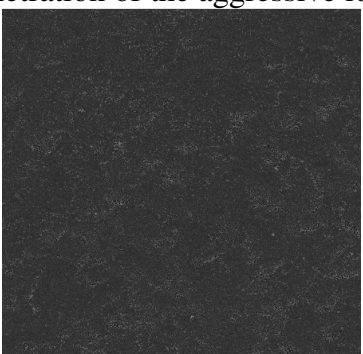

(a)

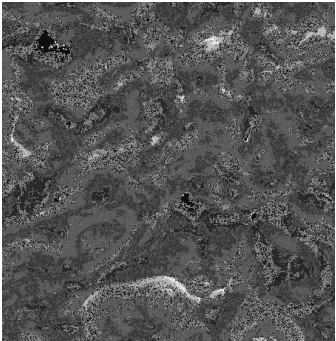

(b)

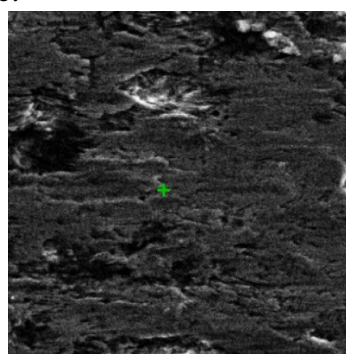

(c)

Figure 8. SEM photograph of mild steel specimens. (a- Fresh, b- Blank, c-with inhibitor)

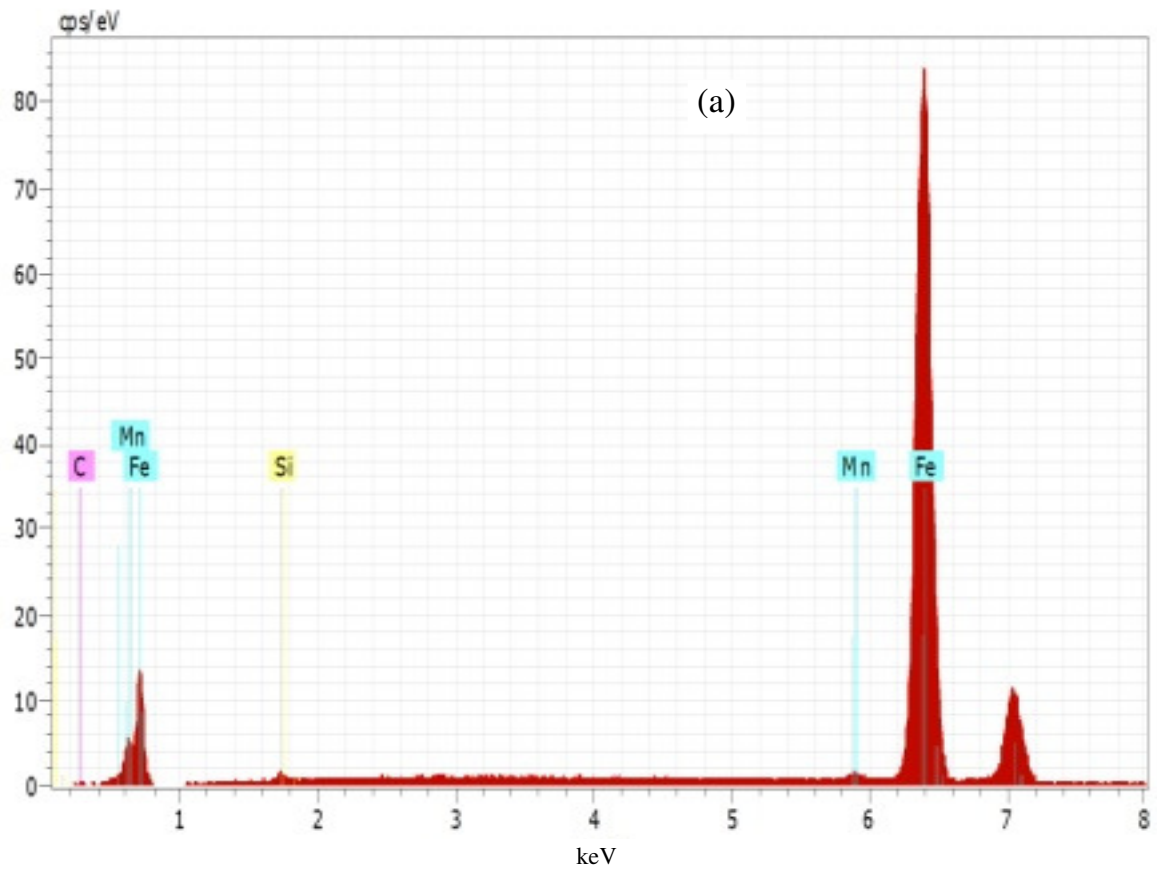



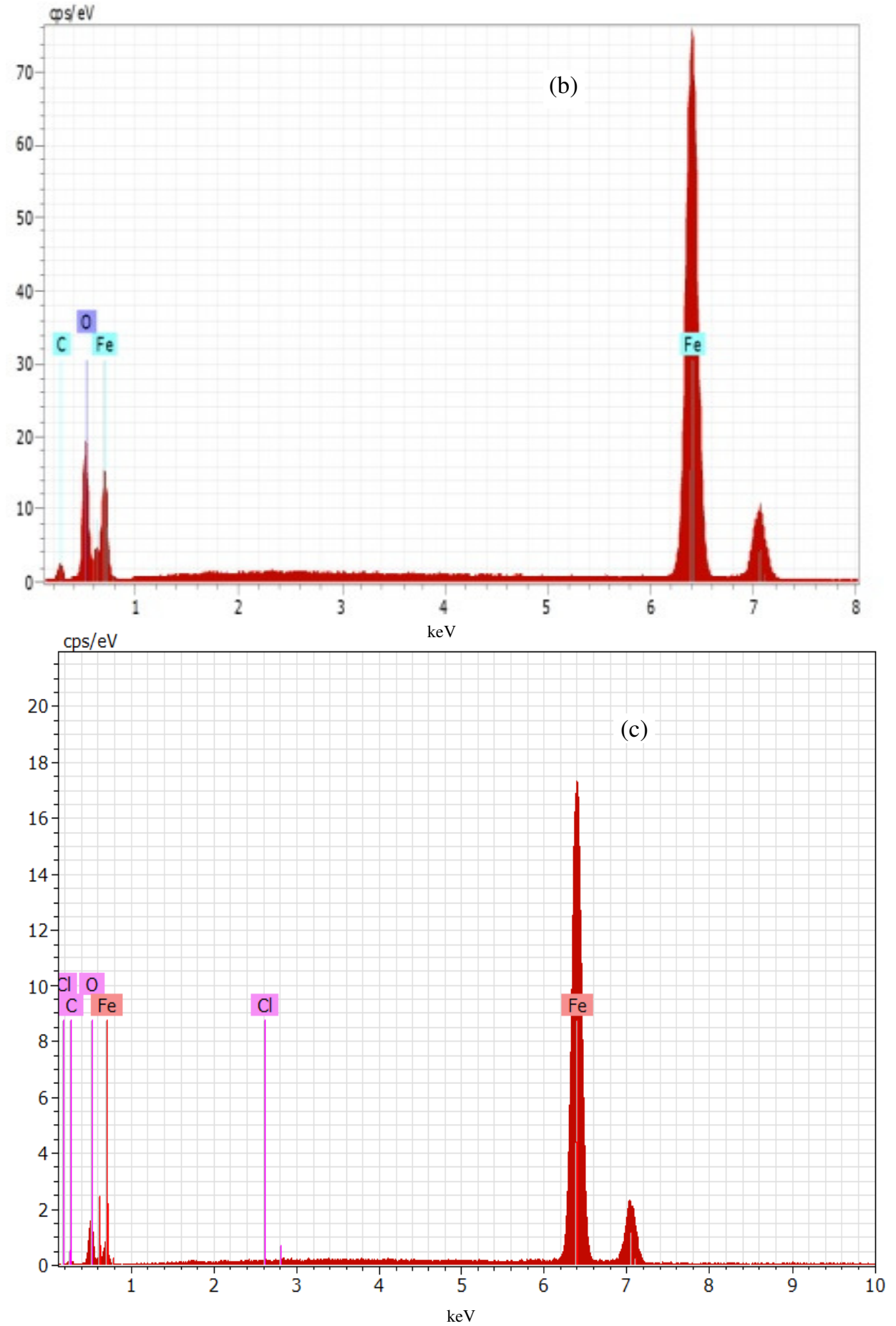

Figure 9. EDX Spectra of the mild steel specimens. (a - Fresh, b - Blank, c -with inhibitor) 
Table 5. Elemental composition of mild steel specimens

\begin{tabular}{cccccc}
\hline \multirow{2}{*}{ Samples } & \multicolumn{5}{c}{ Atomic percentage, \% } \\
\cline { 2 - 6 } & $\mathrm{Fe}$ & $\mathrm{O}$ & $\mathrm{C}$ & $\mathrm{Mn}$ & $\mathrm{Si}$ \\
\hline Pure & 88.59 & - & 10.22 & 0.31 & 0.89 \\
Blank & 31.78 & 46.26 & 21.96 & - & - \\
Inhibited & 57.53 & 29.06 & 13.30 & - & - \\
\hline
\end{tabular}

\section{Conclusion}

2-Hydroxy-4'-methoxy chalcone was found to be an effective inhibitor in the acidic Medium. It provides inhibition efficiency upto $95.85 \%$ in $1 \mathrm{M} \mathrm{H}_{2} \mathrm{SO}_{4}$. Experimentation of the compound follows the Langmuir isotherm. The adsorption is physical in nature. Polarization measurements prove that the compound inhibit both anodic and cathodic reactions. Hence it acts as a mixed type inhibitor. Impendence measurements show that the presence of electron donating group on the inhibitor increases the charge transfer resistance and decreases the double layer capacitance. The substituent group atoms of the inhibitor molecule are found to play an important role in the inhibition process. Results obtained from weight loss measurements and electrochemical measurements are in good agreement. FT-IR analysis confirms that the inhibiton efficiency of the inhibitor in mild steel through electrostatic attraction of inhibitor molecule and the metal surface. The morphological investigation also confirms the effective protection of mild steel, through the less damaged and minimum pits found in the inhibited surface.

\section{References}

1. Ramesh S, Rajeswari S and Maruthamuthu S, Mater Lett., 2003, 57(29), 4547-4554; DOI:10.1016/S0167-577X(03)00360-4

2. Bentiss F, Lagrenee M, Traisnel M and Hornez J C, Corros Sci., 1999, 41(4), 789803; DOI:10.1016/S0010-938X(98)00153-X

3. Paul O A, Ladan M and Takuma S, African Journal of Pure and Applied Chemistry, 2012, 6(7),100-106; DOI: 10.5897/AJPAC12.001

4. Ashisk Kumar Singh, Sudhish Kumar Shukla, Quraishi M A, Int J Electrochem Sci., 2011, 6, 5802-5814.

5. Enkataraman K, The Chemistry of Synthetic Dyes, Academic Press, New York, 1970, p.311.

6. Roberts J D and Caserio M C, "Basic Principles of Organic Chemistry" $2^{\text {nd }}$ Ed., W.A. Benjamin Inc., California, 1979.

7. Talati J D and Gandhi D K, Werkst Korros, 1982, 33, 195.

8. Hasan A, Rasheed L and Abdul Malik, Asian J Chem., 2007, 19(2), 937-948.

9. Kalirajan R, Sivakumar S U, Jubie S, Gowramma B and Suresh B, Int J Chem Tech Res., 2009, 1(1), 27-34.

10. Kalirajan R, Palanivelu M, Rajamanickam V, Vinothapooshan $\mathrm{G}$ and Anandarajagopal K, Int J Chem Sci., 2007, 5(1), 73-80.

11. Udupi R H, Bhat R and Krishna K, Indian J Hetrocycl Chem., 1998, 8, 143-146.

12. Urmila G, Vineeta S, Vineeta K and Sanjana C, Indian J Hetrocycl Chem., 2005, 14, 265; Sci Revs Chem Commun., 2012, 2(2).

13. Pandey V K, Gupta V D and Tiwari D N, Indian J Hetrocycl Chem., 2004, 13, 399-400.

14. Umoren S A, Ogbobe O, Ebenso E E and Ekpe U J, Pigment Resin Technol., 2006, 35(5), 284-292; DOI:10.1108/03699420610692896

15. Umoren S A, Ogbobe O and Ebenso E E, Bull Electrochem., 2006, 22(4), 155-167. 
16. Ebenso E E, Ekpe U J, Umoren S A, Jackson E, Abiola O K and Oforka N C, J Appl Polym Sci., 2006, 100(4), 2889-2894; DOI:10.1002/app.23505

17. Umoren S A and Ebenso E E, Mater Chem Phys., 2007, 106(2-3), 387-393; DOI:10.1016/j.matchemphys.2007.06.018

18. Ebenso E E, Eddy N O and Odiongeyi A O, Portugaliae Electochim Acta., 2009, 27(1), 13-22; DOI:10.4152/pea.200901013

19. Sathiyanarayanan S, Muthkrishnan S and Venkatachari G, Electrochimica Acta., 2006, 51(28), 6313-6319; DOI:10.1016/j.electacta.2006.04.015

20. Eddy N O, Ebenso E E and Ibok U J, J Appl Electrochem., 2010, 40(2), 445-456; DOI:10.1007/s10800-009-0015-Z

21. Tamil Selvi S, Raman V and Rajendran N, J Appl Electrochem., 2003, 33(12), 11751182; DOI:10.1023/B:JACH.0000003852.38068.3f

22. Abboud Y, Abourriche A, Saffaj T, Berrada M, Charrouf M, Bennamara A, AlHimidi N and Hannache H, Mater Chem Phys., 2007, 105(1), 1-5; DOI:10.1016/j.matchemphys.2007.03.037

23. Obi-Egbedi N O and Obot I B, Corros Sci., 2011, 53(1), 263-275; DOI:10.1016/j.corsci.2010.09.020

24. Subramanian N and Ramakrishnaiah K, Indian J Technol., 1970, 8, 369.

25. Niu L, Zhang H, Wei F, Wu S, Cao X and Lui P, Appl Surf Sci., 2005, 252(5), 1634 1642; DOI:10.1016/j.apsusc.2005.02.134

26. Putilova I N, Barannik V P and Balezin S A, Metallic Corrosion Inhibitors, Pergamon Press, Oxford, 1960, 30-32.

27. Chitra S, Parameswari K and Selvaraj A, Int J Electrochem Sci., 2010, 5(11), 1675-1697.

28. Fouda A S, Elmorsi M A and Elmenkkawy A, AfrJ Pure Appl Chem., 2013, 17(10), 337-349; DOI:10.5897/AJPAC2013.0520

29. Talati J D and Darji J M, J Indian Chem Soc., 1988, LXV, 94-99.

30. Agrawal D, Gupta K D and Saxena K K, Trans SAEST, 2003, 38, 111-114.

31. Gunasekaran G and Chauhan L R, Electrochim Acta, 2004, 49(25), 4387-4395; DOI:10.1016/j.electacta.2004.04.030

32. Chitra S, Parameswari K, Vidhya M, Kalishwari M and Selvaraj A, Int J Electrochem Sci., 2011, 6, 4593-4613.

33. Govindaraju K M, Gopi D and Kavitha L, J Appl Electrochem., 2009, 10, 263-269.

34. Singh A, Singh V K and Quraishi M A, Int J Corros., 2010, DOI:10.1155/2010/275983

35. Abualreish M J A, Anwar E M Nor E Ljaleel, Himat M A Fadul, Saad M H Ayuob, Abdel Karim M and Jan H Van Der Westhuizen, Int J Adv Chem., 2015, 3(1), 1-5; DOI:10.14419/ijac.v3i1.3217

36. Sharma Y R, Elementary organic spectroscopy, Principles and Chemical applications, S Chand Publishing, 1992; ISBN: 9788121928847

37. Abd El-Rehim S S, Rwfaey S A, Taha F, Saleh M B and Ahmed R A, J Appl Electrochem., 2001, 31(4), 429-435; DOI:10.1023/A:1017592322277 